\title{
La Exhortación Apostólica del papa Francisco como desafío a los teólogos
}

\author{
Sergio Silva \\ FACULTAD DE TEOLOGÍA \\ PONTIFICIA UNIVERSIDAD CATÓLICA DE CHILE \\ sersilva@uc.cl
}

Resumen: El artículo da cuenta de una lectura de Evangelii Gaudium, a la vez "intencionada" y "personal", que busca descubrir qué desafíos le plantea al teólogo. A partir de la estructura de fondo que se puede descubrir en la Exhortación -un llamado a la conversión para volver a lo esencial del Evangelio, lo que trae consecuencias pastorales- el artículo detecta los correspondientes desafíos para la teología. Entre ellos, no caer en la mera administración de un saber teológico ya constituido, que solo se trataría de preservar; reconocer el aporte de las mujeres en teología; descifrar los signos de los tiempos propios de su cultura; servir a la centralidad del kerygma, sin pretender superarlo mediante la conceptualización teológica; ser teología "en salida" hacia las periferias, optando por los pobres e insertándose el teólogo lo más posible en el pueblo, de manera que su lugar epistemológico se sitúe ahí; respetar la libertad de la Palabra.

Palabras clave: Evangelii Gaudium, teología, kerygma, pueblo, signos de los tiempos, lugar epistemológico.

Abstract: This article focuses on a reading of the Evangelii Gaudium that is both "intentional" and "personal", which seeks to reveal the challenges it may pose to theologians. Based on the foundational structure that may be discovered in the Exhortation -a call to conversion so as a return to the essentials of the gospel, which would lead to pastoral consequencesthis article aims at detecting such challenges for theology. Among them, not ending up in the mere administration of theological knowledge that has already been constituted, which may only aim towards preservation; acknowledging women's role in theology; deciphering the signs of the times in our cultures; serve the centrality of kerygma without the intent to overcome it by means of conceptualizing theology; striving for "outward" theology to the outskirts, focusing on the poor and trying to incorporate 
oneself within the people, thus making them our epistemological reference; and respecting the freedom of the Word.

Keywords: Evangelii Gaudium, theology, kerygma, the people, signs of the times, epistemological reference.

La Exhortación Apostólica Evangelii Gaudium es el primer escrito oficial del papa Francisco en el que expone su pensamiento con bastante amplitud. Este escrito cumple dos objetivos, señalados por él en el $\mathrm{n}^{\circ} 16$ de la Exhortación.

El primero es recoger los trabajos de la XIII Asamblea General Ordinaria del Sínodo de los Obispos sobre "La nueva evangelización para la transmisión de la fe cristiana”, celebrado en Roma en octubre de 2012. Con esto, prolonga una tradición iniciada con la III Asamblea General Ordinaria del Sínodo de los Obispos, iniciada en Roma a fines de septiembre de 1974, que tuvo como tema también la evangelización. En esa oportunidad sucedió que los Padres Sinodales no pudieron llegar a acuerdo sobre un documento final y decidieron entregar al papa Pablo VI los materiales de sus trabajos, para que él decidiera qué hacer con ellos. Pablo VI publicó a fines del año siguiente la admirable Exhortación Apostólica Evangelii Nuntiandi, uno de los escritos más importantes a mi juicio de su pontificado y que sigue vigente. En las Asambleas anteriores del Sínodo de los Obispos los mismos Padres habían redactado un documento de síntesis. Pero desde el Sínodo de 1974 se ha establecido la costumbre de entregar al Papa los resultados, en forma de breves "Proposiciones", que luego él incorpora en una Exhortación Apostólica sobre el tema del Sínodo.

El segundo objetivo de Evangelii Gaudium es "expresar las preocupaciones que me mueven en este momento concreto de la obra evangelizadora de la Iglesia” (EG 16). Es, podríamos decir, una especie de programa de gobierno del papa Francisco. De ahí su importancia.

En este breve artículo doy cuenta de una lectura personal intencionada de Evangelii Gaudium. "Intencionada", en el sentido que me he situado ante el texto como teólogo y he querido dejarme interpelar por él, es decir, he buscado descubrir a qué me desafía en mi tarea teológica. Debo declarar de inmediato que la finalidad de EG no es interpelar a los teólogos; de ahí que mi lectura sea "personal", en cuanto son los 
desafíos que a mi juicio me plantea (y nos plantea a los teólogos) esta Exhortación. Otro teólogo podrá descubrir otros desafíos o matizar de otra manera los que yo he relevado.

Pero no es que EG desconozca el papel de la teología en la tarea evangelizadora de la Iglesia, o se desentienda de él. Por el contrario, en dos números densos se refiere a ese papel con gran claridad y decisión. Vale la pena leerlos sin demasiados comentarios.

"La Iglesia, que es discípula misionera, necesita crecer en su interpretación de la Palabra revelada y en su comprensión de la verdad. La tarea de los exégetas y de los teólogos ayuda a «madurar el juicio de la Iglesia». De otro modo también lo hacen las demás ciencias. (...) Además, en el seno de la Iglesia hay innumerables cuestiones acerca de las cuales se investiga y se reflexiona con amplia libertad. Las distintas líneas de pensamiento filosófico, teológico y pastoral, si se dejan armonizar por el Espíritu en el respeto y el amor, también pueden hacer crecer a la Iglesia, ya que ayudan a explicitar mejor el riquísimo tesoro de la Palabra. A quienes sueñan con una doctrina monolítica defendida por todos sin matices, esto puede parecerles una imperfecta dispersión. Pero la realidad es que esa variedad ayuda a que se manifiesten y desarrollen mejor los diversos aspectos de la inagotable riqueza del Evangelio" (EG 40).

De este número subrayo dos cosas que me parecen de decisiva importancia. En primer lugar, que la tarea de la teología contribuye al crecimiento y maduración de la comprensión que tiene la Iglesia de la Palabra, de la verdad. En segundo lugar, que hay libertad para investigar y para hacer teología de manera no monolítica, uniforme.

El segundo número que se refiere a la teología le asigna una nueva tarea:

"Ya que no basta la preocupación del evangelizador por llegar a cada persona, y el Evangelio también se anuncia a las culturas en su conjunto, la teología -no solo la teología pastoral- en diálogo con otras ciencias y experiencias humanas, tiene gran importancia para pensar cómo hacer llegar la propuesta del Evangelio a la diversidad de contextos culturales y de destinatarios. La Iglesia, empeñada en la evangelización, aprecia y alienta el carisma de los teólogos y su esfuerzo por la investigación teológica, que promueve el diálogo con el mundo de las culturas y de las ciencias. Convoco a los teólogos a cumplir este servicio como parte de la misión salvífica de la Iglesia. 
Pero es necesario que, para tal propósito, lleven en el corazón la finalidad evangelizadora de la Iglesia y también de la teología, y no se contenten con una teología de escritorio" (EG 133).

Es interesante también el inicio del número siguiente, particularmente relevante para los teólogos que trabajamos en facultades universitarias de teología: "Las Universidades son un ámbito privilegiado para pensar y desarrollar este empeño evangelizador de un modo interdisciplinario e integrador" (EG 134). Aquí el Papa subraya el diálogo de la teología con los otros saberes humanos y con las culturas y le asigna un papel importante en la evangelización. Pone también en guardia contra el riesgo de hacer una teología despreocupada del contexto de la misión evangelizadora de la Iglesia, un contexto que la debe marcar profundamente.

Entremos en los desafíos que he relevado como los más significativos para la tarea del teólogo. Voy a proceder citando (o resumiendo) las afirmaciones de la Exhortación, a veces con algún comentario, y señalando a continuación el desafío que descubro en ellas. Pero antes de entrar en las afirmaciones particulares, planteo un desafío general, que surge de lo que podemos llamar el "tono" de la Exhortación.

Creo que el "tono" de EG es nuevo en los documentos pontificios. No es solo que usa un lenguaje a ratos coloquial, incluso con argentinismos que darán mucho dolor de cabeza a los traductores a otras lenguas. Si usa este lenguaje es precisamente por la novedad del "tono". Dos rasgos me parece percibir en esta novedad. Por un lado, el papa Francisco habla de experiencias que todos hacemos (o podemos hacer), de modo que la gente lo comprende. Por otro $-y$ este rasgo es el que me parece más desafiante- no habla desde su rol, sino desde su persona. No es que EG sea una confidencia personal, aunque también hay algunas afirmaciones de ese tipo; ${ }^{1}$ es que el "hablante", el sujeto que uno percibe que se

Por ejemplo, "Me llena de vida releer este texto: «Tu Dios está en medio de ti, poderoso salvador. Él exulta de gozo por ti, te renueva con su amor, y baila por ti con gritos de júbilo» (So 3, 17)" (EG 4); "Comprendo a las personas que tienden a la tristeza por las graves dificultades que tienen que sufrir" (EG 6); "Puedo decir que los gozos más bellos y espontáneos que he visto en mis años de vida son los de personas muy pobres que tienen poco a qué aferrarse" (EG 7); "Sueño con una opción misionera capaz de transformarlo todo" (EG 27); "Agradezco el hermoso ejemplo que me dan tantos cristianos que ofrecen su vida y su tiempo con alegría. Ese testimonio me hace mucho bien y me sostiene en mi propio deseo de superar el egoísmo para entregarme más" (EG 76); "Por ello me duele tanto comprobar cómo en algunas comunidades 
está dirigiendo en el texto a mí como lector, es una persona viva, no un funcionario que cumple un papel, que dice lo que tiene que decir como el funcionario que es.

Pienso que hay aquí un desafío a los teólogos. No se trata ciertamente de convertir la teología en la narración de mi experiencia personal; pero sí de hablar de la experiencia humana y de fe de las personas corrientes. Hay en la Exhortación una afirmación muy válida en esta línea: "Los aparatos conceptuales están para favorecer el contacto con la realidad que pretenden explicar, y no para alejarnos de ella” (EG 194); poco más adelante la refuerza: "La idea -las elaboraciones conceptuales- está en función de la captación, la comprensión y la conducción de la realidad. La idea desconectada de la realidad origina idealismos y nominalismos ineficaces, que a lo sumo clasifican o definen, pero no convocan. Lo que convoca es la realidad iluminada por el razonamiento" (EG 232). Es que "la realidad es superior a la idea" (EG 233). Deberíamos preguntarnos una y otra vez si nuestras conceptualizaciones teológicas ayudan a explicar la realidad del amor de Dios manifestado en Jesús, para comprenderla mejor y, así, nos convocan a vivirla más intensamente, o por el contrario nos alejan de ella.

Entremos ahora en los desafíos puntuales que percibo en ciertas afirmaciones de la Exhortación. Agrupo las afirmaciones y los consiguientes desafíos según los temas que tratan.

cristianas, y aun entre personas consagradas, consentimos diversas formas de odio, divisiones, calumnias, difamaciones, venganzas, celos, deseos de imponer las propias ideas a costa de cualquier cosa, y hasta persecuciones que parecen una implacable caza de brujas" (EG 100); "Ahora quisiera compartir mis inquietudes acerca de la dimensión social de la evangelización" (EG 176); "Por eso quiero una Iglesia pobre para los pobres" (EG 198); “Temo que también estas palabras solo sean objeto de algunos comentarios sin una verdadera incidencia práctica" (EG 201); "Si alguien se siente ofendido por mis palabras, le digo que las expreso con afecto y con la mejor de las intenciones, lejos de cualquier interés personal o ideología política. Mi palabra no es la de un enemigo ni la de un opositor" (EG 208); "Siempre me angustió la situación de los que son objeto de las diversas formas de trata de personas" (EG 211); “Cómo quisiera encontrar las palabras para alentar una etapa evangelizadora más fervorosa, alegre, generosa, audaz, llena de amor hasta el fin y de vida contagiosa!" (EG 261); "Es verdad que esta confianza en lo invisible puede producirnos cierto vértigo: es como sumergirse en un mar donde no sabemos qué vamos a encontrar. Yo mismo lo experimenté tantas veces" (EG 280). 


\section{La Iglesia no PUede SEguir COMO Está, NeCesita CONVERsión}

El papa Francisco es claro y drástico: "Espero que todas las comunidades procuren poner los medios necesarios para avanzar en el camino de una conversión pastoral y misionera, que no puede dejar las cosas como están" (EG 25). Percibo aquí un desafío a los teólogos, a entrar también nosotros en un proceso de conversión pastoral, que tendremos que precisar en sus contenidos específicos, muchos de los cuales podremos entrever a partir de algunos de los desafíos que siguen.

El Papa señala que parte del pueblo bautizado no experimenta su pertenencia a la Iglesia, un hecho -me parece- que cualquiera puede confirmar en su experiencia; y afirma que tenemos que reconocer que eso se debe también al clima poco acogedor, a la actitud burocrática, al predominio de lo administrativo que se percibe en muchas de nuestras parroquias y comunidades (EG 63).

¿Se puede dar este problema en teología? Creo que sí. Por ejemplo, cuando estamos en nuestra labor docente, sea en la Academia, sea en charlas de difusión, ‘̇acogemos las preguntas y las inquietudes que plantean los auditores, o impedimos el diálogo con sentencias doctrinales seguras, que sabemos administrar? Dicho de otra manera, el desafío es a no convertirnos en burócratas de la verdad oficial, a escuchar las dudas del pueblo de Dios y a acoger sus descubrimientos para enriquecer nuestra teología con ellos.

\section{Dice Francisco:}

"Es verdad que, en nuestra relación con el mundo, se nos invita a dar razón de nuestra esperanza, pero no como enemigos que señalan y condenan. (...). Queda claro que Jesucristo no nos quiere príncipes que miran despectivamente, sino hombres y mujeres de pueblo. Ésta no es la opinión de un Papa ni una opción pastoral entre otras posibles; son indicaciones de la Palabra de Dios tan claras, directas y contundentes que no necesitan interpretaciones que les quiten fuerza interpelante. Vivámoslas «sine glossa», sin comentarios" (EG 271).

Pienso que muchas veces los teólogos hacemos nuestra teología con esta actitud condenatoria, como si nosotros fuéramos impecables, o la verdad que estamos exponiendo fuera definitiva, no admitiera ni contradicción ni nuevos desarrollos. Creo que la pregunta que nos tenemos 
que hacer es si nos dejamos interpelar por las preguntas que nos llegan y por los hechos que suceden, o condenamos.

Ya he citado el número en el que el Papa habla de la necesidad de una conversión pastoral y misionera de la Iglesia. Inmediatamente a continuación dice: "Ya no nos sirve una "simple administración». Constituyámonos en todas las regiones de la tierra en un "estado permanente de misión»" (EG 25).

El Papa se refiere a la Iglesia, no a la teología. Sin embargo, me parece útil y necesario trasladar la pregunta también a la teología: ¿Qué significa para el quehacer teológico -el mío y el de los teólogos, en generalesta contraposición entre conversión y administración? Podemos decir que se "administra" un sistema ya establecido, con reglas claras, que solo se trata de aplicar adecuadamente; una especie de juego de ajedrez, que tiene posibilidades de variaciones nuevas, pero siempre dentro de un espacio acotado. La "conversión”, en cambio, habría que entenderla como la apertura a la novedad del Espíritu de Dios. Nos puede iluminar otra afirmación del Papa: "La Palabra tiene en sí una potencialidad que no podemos predecir. El Evangelio habla de una semilla que, una vez sembrada, crece por sí sola también cuando el agricultor duerme (cf. Mc 4, 26-29). La Iglesia debe aceptar esa libertad inaferrable de la Palabra, que es eficaz a su manera, y de formas muy diversas que suelen superar nuestras previsiones y romper nuestros esquemas" (EG 22). Si la Iglesia debe aceptar esa libertad, también, por supuesto, debe hacerlo la teología. La conversión consiste, entonces, en estar abiertos a esa Palabra que nunca podremos domesticar enteramente, que siempre conservará su prioridad con respecto a nuestras conceptualizaciones, por lo que las afectará con una marca de provisoriedad y de inadecuación radicales.

Poco más adelante, el papa Francisco dice que todo en la Iglesia debe convertirse "en un cauce adecuado para la evangelización del mundo actual más que para la autopreservación" (EG 27).

Hay aquí una segunda contraposición, esta vez entre evangelización del mundo y autopreservación de la Iglesia. Aunque este contraste está referido a la Iglesia, creo que tenemos que plantearlo también para nuestro quehacer como teólogos. ¿Qué significa para el quehacer teológico esta contraposición? Podríamos decir que una teología que fuera cauce para la autopreservación de la Iglesia sería una "teología de corte" o "cortesana", es decir, una teología que se empeña en dar fundamento y 
sustento a la Iglesia tal como está; dicho de otro modo, una teología que se pone al servicio del poder eclesiástico, sea el de los grupos y personas que en un momento dado lo tienen, sea el de los que luchan por tenerlo. Peor aun sería una teología dedicada a su propia autopreservación, como ha sido el caso de escuelas teológicas - por ejemplo, la neoescolástica de la segunda mitad del siglo XIX- que han buscado su propia perpetuación. La tarea de la teología no puede ser el servicio a ninguna autopreservación, porque, siendo de Iglesia, debe estar volcada, como ella, al servicio del Evangelio de Jesús.

En varios números el Papa toca aspectos muy precisos que podemos vincular al lado negativo de los dos contrastes recién señalados, la administración y la autopreservación. Uno es el riesgo del encierro; lo plantea a propósito de la actividad y la vida de los agentes pastorales, en especial de los sacerdotes: "Salir de sí mismo para unirse a otros hace bien. Encerrarse en sí mismo es probar el amargo veneno de la inmanencia, y la humanidad saldrá perdiendo con cada opción egoísta que hagamos" (EG 87). Como teólogos, ¿no experimentamos una y otra vez la tentación de encerrarnos en los grupos que piensan como nosotros o en los temas que hemos aprendido a manejar? Cuando nos encerramos, perdemos la riqueza del diálogo con los diferentes que, al cuestionar nuestras posiciones, nos obligan a revisar sus fundamentos. Y cuando no estamos abiertos a todos los temas, perdemos la riqueza de la realidad y de los desafíos que nos plantea.

En el mismo contexto, se refiere al peligro del "neopelagianismo autorreferencial y prometeico de quienes en el fondo solo confían en sus propias fuerzas y se sienten superiores a otros por cumplir determinadas normas o por ser inquebrantablemente fieles a cierto estilo católico propio del pasado. Es una supuesta seguridad doctrinal o disciplinaria que da lugar a un elitismo narcisista y autoritario, donde en lugar de evangelizar lo que se hace es analizar y clasificar a los demás, y en lugar de facilitar el acceso a la gracia se gastan las energías en controlar" (EG 94). ¿No corremos los teólogos también este riesgo de caer en una fidelidad inquebrantable a determinadas formulaciones, sean del pasado o de nuestra propia elaboración, y de buscar en esa fidelidad una supuesta seguridad doctrinal? En cuyo caso no estaríamos contribuyendo a la evangelización sino a la clasificación de las afirmaciones teológicas en 
verdaderas -las que están de acuerdo con las mías- o heréticas, las que están en desacuerdo.

Hacia el final de la Exhortación el papa Francisco nos pone en guardia contra un último factor de encierro, quizá el de mayor peso: "Puede suceder que el corazón se canse de luchar porque en definitiva se busca a sí mismo en un carrerismo sediento de reconocimientos, aplausos, premios, puestos" (EG 277). Los teólogos no estamos exentos de buscarnos a nosotros mismos.

Pienso que estos tres aspectos concretos que plantea la Exhortación deberían ser objeto de un examen personal ante Dios, para descubrir con la mayor honestidad posible si se dan en mí y de qué maneras precisas. Pero deberíamos también tratar de ayudarnos entre nosotros, en la medida de la confianza que podamos tener unos con otros, a luchar contra estas tentaciones.

En dos números de la Exhortación el Papa afirma que hay que dar más espacio a la mujer en la Iglesia (EG 103-104). Lo dice primero en general: "todavía es necesario ampliar los espacios para una presencia femenina más incisiva en la Iglesia” (EG 103). Pero esta vez se refiere también expresamente a la teología: "Reconozco con gusto cómo muchas mujeres comparten responsabilidades pastorales junto con los sacerdotes, contribuyen al acompañamiento de personas, de familias o de grupos y brindan nuevos aportes a la reflexión teológica” (EG 103).

Cada uno como teólogo debe preguntarse si reconoce ese aporte nuevo de las mujeres teólogas, si los incorpora en su propia reflexión. Porque fácilmente puede suceder que los dejemos de lado como "cosas de mujeres”, respetables en su propio ámbito, pero sin mayor proyección universal. Me parece que es también un desafío el tema de la integración de las mujeres tanto en las Facultades de teología como en todos los lugares donde se reflexiona teológicamente, para evitar que se produzca un aislamiento institucional del quehacer teológico de las mujeres, que les coarte su influencia en el conjunto de la teología y las prive del diálogo, siempre desafiante, con la teología de los otros.

El capítulo $2^{\circ}$ de la EG está dedicado a hacer un diagnóstico de los desafíos que enfrenta la evangelización hoy, tanto los que vienen del mundo como los que proceden de las "tentaciones de los agentes pasto- 
rales”, como titula Francisco la segunda sección de ese capítulo. Al final del capítulo dice:

"Como ya dije, no he intentado ofrecer un diagnóstico completo, pero invito a las comunidades a completar y enriquecer estas perspectivas a partir de la conciencia de sus desafíos propios y cercanos. Espero que, cuando lo hagan, tengan en cuenta que, cada vez que intentamos leer en la realidad actual los signos de los tiempos, es conveniente escuchar a los jóvenes y a los ancianos. Ambos son la esperanza de los pueblos. Los ancianos aportan la memoria y la sabiduría de la experiencia, que invita a no repetir tontamente los mismos errores del pasado. Los jóvenes nos llaman a despertar y acrecentar la esperanza, porque llevan en sí las nuevas tendencias de la humanidad y nos abren al futuro, de manera que no nos quedemos anclados en la nostalgia de estructuras y costumbres que ya no son cauces de vida en el mundo actual" (EG 108).

Aquí el Papa plantea un desafío teológico de enorme importancia, recogido ya en la Constitución Gaudium et spes del Concilio; el desafío de "leer en la realidad actual los signos de los tiempos". Lo interesante, me parece, es que invita a las diversas comunidades de la Iglesia a hacer esta lectura en su propia realidad, tomando conciencia de "sus desafíos propios y cercanos". No hay una lectura universal de los signos de los tiempos, estos son diversos según las diversas realidades del mundo. Y para hacer esta lectura hay que escuchar la voz de los ancianos y de los jóvenes, en un diálogo mutuamente enriquecedor, tratando de evitar cualquier unilateralidad. Ciertamente, la tarea de leer los signos de los tiempos en la realidad es una tarea que supera y desborda las posibilidades de un teólogo individual; se requiere, por lo tanto, la colaboración de muchos. Las Facultades de teología y los diversos Centros de investigación pueden ofrecer la infraestructura institucional adecuada para esta labor conjunta. Encuentros entre Facultades y Centros de una misma región - por ejemplo, de América Latina- pueden ser inmensamente positivos para compartir las diversas lecturas e ir descubriendo signos de los tiempos más globales. Y, dada la actual globalización, se hacen urgentes los encuentros internacionales, para detectar los signos que están afectando al mundo entero. A mi juicio, enfrentar este desafío de leer los signos de los tiempos es un requisito indispensable para lograr la conversión de la Iglesia y de la teología, porque se trata de escuchar la voz de Dios en la historia que nos toca vivir, es decir, descubrir qué quiere Dios de nosotros, aquí, hoy. 
2. La misión CONSISTE en Llevar el EVAngelio, QUe es EL AMOR De Dios MANIFESTADO EN JESÚS

El papa Francisco deja muy en claro que la conversión a la que está llamando a la Iglesia es para centrarse en lo esencial. "Una pastoral en clave misionera no se obsesiona por la transmisión desarticulada de una multitud de doctrinas que se intenta imponer a fuerza de insistencia. Cuando se asume un objetivo pastoral y un estilo misionero, que realmente llegue a todos sin excepciones ni exclusiones, el anuncio se concentra en lo esencial, que es lo más bello, lo más grande, lo más atractivo y al mismo tiempo lo más necesario. La propuesta se simplifica, sin perder por ello profundidad y verdad, y así se vuelve más contundente y radiante" (EG 35). Y prosigue, de inmediato:

"Todas las verdades reveladas proceden de la misma fuente divina y son creídas con la misma fe, pero algunas de ellas son más importantes por expresar más directamente el corazón del Evangelio. En este núcleo fundamental lo que resplandece es la belleza del amor salvifico de Dios manifestado en Jesucristo muerto y resucitado. En este sentido, el Concilio Vaticano II explicó que «hay un orden o 'jerarquía' en las verdades en la doctrina católica, por ser diversa su conexión con el fundamento de la fe cristiana $»^{2}$. Esto vale tanto para los dogmas de fe como para el conjunto de las enseñanzas de la Iglesia, e incluso para la enseñanza moral" (EG 36).

Se ve claramente que lo esencial de toda la vida de la fe y, por lo tanto, de la Iglesia y de la teología, es el amor de Dios manifestado en la Pascua de Jesús.

Más adelante, lo dice de otra manera, igualmente clara y decisiva. El contexto es el de la catequesis:

"Hemos redescubierto que también en la catequesis tiene un rol fundamental el primer anuncio o "kerygma», que debe ocupar el centro de la actividad evangelizadora y de todo intento de renovación eclesial. El kerygma es trinitario. Es el fuego del Espíritu que se dona en forma de lenguas y nos hace creer en Jesucristo, que con su muerte y resurrección nos revela y nos comunica la misericordia infinita del Padre. [...]. Cuando a este primer anuncio se le llama "primero", eso no significa que está al comienzo y después se olvida o se reemplaza por otros contenidos que lo superan. Es el primero en un sentido

2 La cita es del Concilio Vaticano II, Decreto Unitatis redintegratio, sobre el ecumenismo, 11. 
cualitativo, porque es el anuncio principal, ese que siempre hay que volver a escuchar de diversas maneras y ese que siempre hay que volver a anunciar de una forma o de otra a lo largo de la catequesis, en todas sus etapas y momentos" (EG 164).

Lo que vale para la catequesis vale ciertamente también para la teología. El kerygma es la realidad a la que las conceptualizaciones teológicas deben acercarnos lo mejor y más posible, de la que no deben alejarnos, recordando la advertencia de Francisco que ya hemos citado (EG 194).

En otros pasajes el Papa aborda un aspecto de lo esencial del kerygma: la primacía de la gracia de Dios, del don. "La salvación que Dios nos ofrece es obra de su misericordia. No hay acciones humanas, por más buenas que sean, que nos hagan merecer un don tan grande. Dios, por pura gracia, nos atrae para unirnos a sí. [...] El principio de la primacía de la gracia debe ser un faro que alumbre permanentemente nuestras reflexiones sobre la evangelización” (EG 112). La misma primacía del don se descubre en la Escritura; en el contexto de cómo debe ser la homilía, el Papa afirma: "La memoria del pueblo fiel, como la de María, debe quedar rebosante de las maravillas de Dios. Su corazón, esperanzado en la práctica alegre y posible del amor que se le comunicó, siente que toda palabra en la Escritura es primero don antes que exigencia" (EG 142). Finalmente, vuelve sobre el tema en el contexto del crecimiento en la fe y de la profundización del kerygma:

"Por otra parte, este camino de respuesta y de crecimiento está siempre precedido por el don, porque lo antecede aquel otro pedido del Señor: «bautizándolos en el nombre...» $(M t 28,19)$. La filiación que el Padre regala gratuitamente y la iniciativa del don de su gracia (cf. Ef 2, 8-9; 1 Co 4, 7) son la condición de posibilidad de esta santificación constante que agrada a Dios y le da gloria" (EG 162).

Todas estas afirmaciones apuntan a un desafío radical a la teología que cada uno de nosotros hace, un desafío que debe convertirse en tema de reflexión y examen personal permanente.

En coherencia con la primacía de la gracia la Exhortación afirma que todo en la Iglesia ha de estar fundado en la Escritura. 174. "No solo la homilía debe alimentarse de la Palabra de Dios. Toda la evangelización está fundada sobre ella, escuchada, meditada, vivida, celebrada y testimoniada. Las Sagradas Escrituras son fuente de la evangelización. Por lo tanto, hace falta formarse continuamente en la escucha de la Palabra. 
La Iglesia no evangeliza si no se deja continuamente evangelizar. Es indispensable que la Palabra de Dios «sea cada vez más el corazón de toda actividad eclesial»3" (EG 174). La homilía, la evangelización, toda actividad eclesial: hay una progresión que va ampliando el radio de lo que debe fundarse en la Escritura. Como la teología es una actividad eclesial, a ella también le cabe fundarse en la Escritura.

Aquí se puede plantear el problema, que se arrastra a medio resolver desde que se instaló en las Iglesias la exégesis científica, de cómo puede el teólogo basar su quehacer en la Escritura. ¿Está obligado a depender del exégeta? Como la exégesis, gracias a Dios, hoy ya no es monocordemente histórico-crítica, ¿¿de qué corriente debe depender? O bien, ¿puede atreverse a hacer una lectura teológica de la Escritura, apoyándose en los resultados de la exégesis que le parezcan confiables y adecuados para su tarea? ¿Es posible un diálogo entre los teólogos y los exégetas acerca de la interpretación de la Escritura, no para llegar a una interpretación única considerada como auténtica, sino, más bien, para enriquecerse mutuamente y ampliar los respectivos horizontes de comprensión? Las preguntas se pueden multiplicar y precisar mucho más. Basten las anotadas para mostrar que el problema para el teólogo $-\mathrm{y}$, a mi entender, también para el predicador y para todos los que están involucrados en las diversas actividades eclesiales- no es de solución fácil. Quizá hay aquí una hermosa tarea para los mismos teólogos, en diálogo con los exégetas; y ambos dialogantes con "un oído en el pueblo", como pide Francisco expresamente a los predicadores (EG 154).

El tema de la Escritura, tal como lo presenta el Papa, trae un segundo desafío: "El estudio de las Sagradas Escrituras debe ser una puerta abierta a todos los creyentes ${ }^{4}$. [...] La evangelización requiere la familiaridad con la Palabra de Dios y esto exige a las diócesis, parroquias y a todas las agrupaciones católicas, proponer un estudio serio y perseverante de la Biblia, así como promover su lectura orante personal y comunitaria” (EG 175). El desafío a la teología que entreveo aquí es cómo colaborar eficazmente en abrir la puerta de la Escritura - del estudio de la Biblia, como precisa Francisco- a todos los creyentes. Se trata de que los cristianos puedan estudiar la Biblia, no solo leerla ni orar con ella. Porque

3 La cita es de Benedicto XVI, Exhortación apostólica postsinodal Verbum Domini (30 septiembre 2010), 1.

4 El Papa recoge aquí la "Propositio" 11 de los Padres sinodales. 
el estudio enriquecerá inmensamente su lectura y su oración. Me temo que los teólogos estemos aquí en deuda.

La vuelta a lo esencial, afirma la Exhortación, supone no romper la proporción que debe haber entre las diversas verdades de la fe. Esta proporción se rompe "cuando se habla más de la ley que de la gracia, más de la Iglesia que de Jesucristo, más del Papa que de la Palabra de Dios” (EG 38). Podríamos decir que en estos casos se está poniendo "la carreta delante de los bueyes", es decir, se está impidiendo el movimiento de la fe.

Este es también un desafío crucial al teólogo, a no perder nunca de vista el centro de la fe, el kerygma de la Pascua de Jesús, en la que se ha manifestado de manera culminante el amor de Dios, gratuito, inmerecido, inmerecible.

\section{Consecuencias para la teología}

La Exhortación saca algunas consecuencias para la Iglesia de lo ya dicho sobre la necesidad de una conversión pastoral y de volver a lo esencial del Evangelio. Pero esas consecuencias implican también desafíos para los teólogos. Me detengo en cuatro de estas consecuencias.

En primer lugar, el papa Francisco quiere una Iglesia "en salida". Sus palabras son claras y fuertes. "En la Palabra de Dios aparece permanentemente este dinamismo de «salida» que Dios quiere provocar en los creyentes" (EG 20). Y, luego de poner los ejemplos de Abrahán, Moisés, Jeremías y de Jesús, concluye: "Cada cristiano y cada comunidad discernirá cuál es el camino que el Señor le pide, pero todos somos invitados a aceptar este llamado: salir de la propia comodidad y atreverse a llegar a todas las periferias que necesitan la luz del Evangelio" (EG 20). Poco más adelante, vuelve sobre el tema: "Salgamos, salgamos a ofrecer a todos la vida de Jesucristo. Repito aquí para toda la Iglesia lo que muchas veces he dicho a los sacerdotes y laicos de Buenos Aires: prefiero una Iglesia accidentada, herida y manchada por salir a la calle, antes que una Iglesia enferma por el encierro y la comodidad de aferrarse a las propias seguridades" (EG 49). De nuevo: "Esta salvación, que realiza Dios y anuncia gozosamente la Iglesia, es para todos [...]. Jesús no dice a los Apóstoles que formen un grupo exclusivo, un grupo de élite. Jesús dice: «Vayan y hagan que todos los pueblos sean mis discípulos» $(M t 28,19)$ ) (EG 113). Finalmente recojo un último texto: "Esta inseparable conexión entre la recepción del anuncio salvífico y un efectivo amor fraterno está expresada en algunos 
textos de las Escrituras que conviene considerar y meditar detenidamente para extraer de ellos todas sus consecuencias"; luego de citar Mt 7, 2; 25 , 40 y Lc 6, 36-38, concluye: "Lo que expresan estos textos es la absoluta prioridad de la «salida de sí hacia el hermano» como uno de los dos mandamientos principales que fundan toda norma moral y como el signo más claro para discernir acerca del camino de crecimiento espiritual en respuesta a la donación absolutamente gratuita de Dios" (EG 179).

Si el desafío vale para la Iglesia en su conjunto y para cada cristiano en ella, creo que vale también para la teología en cuanto tal. Entonces cabe la pregunta, ¿qué puede significar una teología "en salida”? ¿Cuáles son las "periferias" a las que se debe acercar la teología? Como se trata de pensar la fe, me parece que el teólogo debe atreverse a salir de lo ya sabido y exponerse a las nuevas preguntas y a los cuestionamientos de su presente; debe atreverse también a buscar los signos de la presencia o ausencia de Dios en la historia que le toca vivir. Porque es ahí donde están los hermanos hacia los cuales tiene que salir, dejando sus seguridades. $\mathrm{Y}$ ¿qué puede significar una teología "accidentada, herida y manchada por salir a la calle”? ¿y un teólogo igualmente accidentado? Creo que los pensadores que se atrevieron a pensar la fe a la altura de los desafíos de su tiempo son un buen ejemplo; entre ellos, Tomás, Newman, Rahner, Teilhard de Chardin y tantos otros. Hicieron un esfuerzo que a muchos en la Iglesia les pareció heterodoxo, quizá porque no decían lo mismo que ellos. Pero fue gracias a estos audaces que la teología no se anquilosó y pudo hacer un aporte importante, a veces decisivo, al conjunto de la Iglesia.

Un segundo desafío es la prioridad de los pobres. De nuevo, las palabras del Papa son claras y punzantes. Cito algunas. "Basta recorrer las Escrituras para descubrir cómo el Padre bueno quiere escuchar el clamor de los pobres" (EG 187). En el número siguiente afirma que todos en la Iglesia debemos cooperar "para resolver las causas estructurales de la pobreza y para promover el desarrollo integral de los pobres” (EG 188). Luego de recordar el mensaje de la Escritura y de los Padres sobre la misericordia para con los pobres, dice: "Es un mensaje tan claro, tan directo, tan simple y elocuente, que ninguna hermenéutica eclesial tiene derecho a relativizarlo. [...]. Jesús nos enseñó este camino de reconocimiento del otro con sus palabras y con sus gestos. ¿Para qué oscurecer lo que es tan claro? No nos preocupemos solo por no caer en errores 
doctrinales, sino también por ser fieles a este camino luminoso de vida y de sabiduría" (EG 194). Luego de referirse a la opción por los pobres como una "categoría teológica antes que cultural, sociológica, política o filosófica”, afirma:

"Por eso quiero una Iglesia pobre para los pobres. Ellos tienen mucho que enseñarnos. Además de participar del sensus fidei, en sus propios dolores conocen al Cristo sufriente. Es necesario que todos nos dejemos evangelizar por ellos. La nueva evangelización es una invitación a reconocer la fuerza salvífica de sus vidas y a ponerlos en el centro del camino de la Iglesia. Estamos llamados a descubrir a Cristo en ellos, a prestarles nuestra voz en sus causas, pero también a ser sus amigos, a escucharlos, a interpretarlos y a recoger la misteriosa sabiduría que Dios quiere comunicarnos a través de ellos" (EG 198).

Y en el número siguiente, dice que solo desde una "cercanía real y cordial podemos acompañarlos adecuadamente en su camino de liberación. Únicamente esto hará posible que los pobres, en cada comunidad cristiana, se sientan como en su casa" (EG 199). Dos números después insiste: "Nadie debería decir que se mantiene lejos de los pobres porque sus opciones de vida implican prestar más atención a otros asuntos. Esta es una excusa frecuente en ambientes académicos, empresariales o profesionales, e incluso eclesiales" (EG 201). Un último texto desafiante: "Cualquier comunidad de la Iglesia, en la medida en que pretenda subsistir tranquila sin ocuparse creativamente y cooperar con eficiencia para que los pobres vivan con dignidad y para incluir a todos, también correrá el riesgo de la disolución, aunque hable de temas sociales o critique a los gobiernos. Fácilmente terminará sumida en la mundanidad espiritual, disimulada con prácticas religiosas, con reuniones infecundas o con discursos vacíos" (EG 207). Hacia el final de esta larga sección dedicada al tema de los pobres, incluye entre ellos también a la creación, de la que debemos igualmente cuidar: "Hay otros seres frágiles e indefensos, que muchas veces quedan a merced de los intereses económicos o de un uso indiscriminado. Me refiero al conjunto de la creación. Los seres humanos no somos meros beneficiarios, sino custodios de las demás creaturas" (EG 215).

Vinculado estrechamente al tema de los pobres está la insistencia -quizá la más frecuente en la Exhortación- en que los pastores, y la Iglesia en general, deben convertirse en pueblo (EG 220), ser pueblo (EG 273), tener cercanía con el pueblo (EG 135, 268), estar en el corazón 
del pueblo (EG 269), tener un oído puesto en el pueblo (EG 154), escuchar su fe (EG 139), compartir la vida con el pueblo (EG 269, 271), ser "hombres y mujeres de pueblo" (EG 271), estar en contacto con él (EG 28, 82), con su realidad sufrida (EG 96), construyendo un mundo nuevo "codo a codo con los demás" (EG 269). Francisco exclama: "Es lindo ser pueblo fiel de Dios. ¡Y alcanzamos plenitud cuando rompemos las paredes y el corazón se nos llena de rostros y de nombres!” (EG 274).

El desafío que parece desprenderse de estos textos intensos es doble. Por un lado, se dirige claramente a la persona del teólogo, que debería tratar de cumplir todo lo que aquí dice Francisco. Pero se dirige también -aunque el Papa no lo explicite- a la teología que hacemos los teólogos. Para que sea auténtica teología, debe ser hecha en la escucha atenta del clamor de los pobres, porque Dios los escucha y porque, en su sentido de fe, tienen mucho que enseñarnos; para ello, el teólogo debe estar cerca de los pobres, sin buscar excusas de ningún tipo. Dicho de otra manera, su lugar epistemológico -el horizonte desde el cual hace su teología- debe estar lo más posible en el pueblo de los pobres. Además, debe intentar colaborar, en cuanto teología, en la solución de las causas estructurales de la pobreza, haciendo la crítica de los malentendidos respecto del valor evangélico de los pobres, que han sido alentados por determinadas teologías, pero que han impedido o dificultado trabajar por una solución de esas causas estructurales. Por último, la teología debe mantener siempre clara la jerarquía de las verdades, de manera de no preocuparse en primer lugar de los errores doctrinales sino de iluminar el camino del Evangelio. Es interesante que Francisco incluya la preocupación ecológica en esta sección sobre los pobres, porque eso significa que reconoce que la naturaleza es también creatura de Dios, que la ama, y que está siendo maltratada, al igual que tantos pobres y excluidos. Percibo aquí un llamado a los teólogos -no solo a los que hacen el tratado de creación o de moral- a integrar en sus trabajos esta perspectiva.

El tercer desafío proviene de lo que para el Papa es la actitud pastoral fundamental, que es el amor. Lo dice de manera sucinta: "Ser discípulo es tener la disposición permanente de llevar a otros el amor de Jesús" (EG 127). El teólogo es también discípulo, no solo en cuanto individuo creyente sino en cuanto teólogo. El desafío es, entonces, hacer que el amor de Jesús esté en el centro mismo de la teología que elabora y que no sea un añadido extrínseco, meramente piadoso. Esto supone un ejer- 
cicio no pura y exclusivamente racional de la razón en teología, sino uno que se esfuerce permanentemente por arraigar en el corazón, ese centro donde se integran la razón, la libertad y el amor.

El amor que el papa Francisco propone aparece en la Exhortación con dos rasgos principales, que se condicionan a mi entender el uno al otro. Es un amor paciente y que sabe comunicar. Sobre la paciencia, baste con dos textos. "Por lo tanto, sin disminuir el valor del ideal evangélico, hay que acompañar con misericordia y paciencia las etapas posibles de crecimiento de las personas que se van construyendo día a día"; y añade: "Un pequeño paso, en medio de grandes límites humanos, puede ser más agradable a Dios que la vida exteriormente correcta de quien transcurre sus días sin enfrentar importantes dificultades" (EG 44). "Tenemos que darle a nuestro caminar el ritmo sanador de projimidad, con una mirada respetuosa y llena de compasión pero que al mismo tiempo sane, libere y aliente a madurar en la vida cristiana" (EG 169). Creo que la teología puede hacer el esfuerzo por fundamentar adecuadamente esta paciencia. Por ejemplo, elaborando una teoría del desarrollo de la fe, que contemple las diversas etapas por las que va pasando, de acuerdo, por un lado, a las etapas del desarrollo sicológico de la persona y a sus rasgos de personalidad, y, por otro, a las circunstancias en que ha vivido y en que vive; de manera que no se imponga un modelo acabado y monolítico de la vida de la fe, que puede ser aplastante al punto de desanimar a los fieles. Además, la teología puede ayudar a derribar los prejuicios teológicos que han dificultado tener esta actitud paciente.

Saber comunicar supone tener paciencia con el interlocutor y reconocer su real capacidad de escucha y de comprensión, al mismo tiempo que estar dispuesto a escucharlo de verdad. Esta característica del amor pastoral se hace hoy particularmente necesaria, por el cambio cultural. "Al mismo tiempo, los enormes y veloces cambios culturales requieren que prestemos una constante atención para intentar expresar las verdades de siempre en un lenguaje que permita advertir su permanente novedad. Pues en el depósito de la doctrina cristiana «una cosa es la substancia [...] y otra la manera de formular su expresión» [cita del discurso de Juan XXIII al inaugurar el Concilio]. A veces, escuchando un lenguaje completamente ortodoxo, lo que los fieles reciben, debido al lenguaje que ellos utilizan y comprenden, es algo que no responde al verdadero Evangelio de Jesucristo. Con la santa intención de comunicarles la ver- 
dad sobre Dios y sobre el ser humano, en algunas ocasiones les damos un falso dios o un ideal humano que no es verdaderamente cristiano. De ese modo, somos fieles a una formulación, pero no entregamos la substancia. Ese es el riesgo más grave" (EG 41). El Papa insiste en este punto: "No hay que pensar que el anuncio evangélico deba transmitirse siempre con determinadas fórmulas aprendidas, o con palabras precisas que expresen un contenido absolutamente invariable. Se transmite de formas tan diversas que sería imposible describirlas o catalogarlas, donde el Pueblo de Dios, con sus innumerables gestos y signos, es sujeto colectivo" (EG 129). Añade una afirmación poderosa: "Las expresiones de la piedad popular tienen mucho que enseñarnos y, para quien sabe leerlas, son un lugar teológico al que debemos prestar atención, particularmente a la hora de pensar la nueva evangelización” (EG 126). Junto al cambio cultural hay que tener en cuenta la diversidad de culturas con las que hoy estamos todos en contacto; el anuncio debe atender a la cultura de los interlocutores (puede verse EG 115, 117, 121, 123, 124, 126). A propósito de la homilía, dice Francisco: "Recordemos que nunca hay que responder preguntas que nadie se hace; tampoco conviene ofrecer crónicas de la actualidad para despertar interés: para eso ya están los programas televisivos" (EG 155); así, a mi entender, sitúa los dos extremos en los que el predicador (y también el teólogo, habría que añadir) no debe caer, ambos sin trascendencia, insignificantes para su auditorio.

La tarea que se desprende para el teólogo de estas indicaciones pastorales del Papa es inmensa. ¿Cómo tener en cuenta la cultura en una época de cambios tan rápidos, de manera de buscar respuesta a las preguntas reales de la gente, pero sin echar por la borda la necesaria y lenta reflexión que permita madurar la búsqueda? Además, dada la aceleración del cambio cultural, las preguntas cambian con gran rapidez; ¿es posible seguirles el tranco? Por otra parte, habría que aceptar al pueblo de Dios como sujeto auténtico de la teología y aprender a escuchar su voz, incorporando su teologizar en el de la teología profesional y académica, sobre todo si las expresiones de la piedad popular son un auténtico lugar teológico. En cuanto a responder preguntas que nadie se hace, se plantea un problema de no fácil solución, porque en teología hay que enseñar respuestas ya hechas a preguntas de antes, y los programas de enseñanza en seminarios y facultades fuerzan a pasar determinadas materias. ¿Cómo hacerlo desde las preguntas reales de hoy? 
El cuarto y último desafío que quiero presentar tiene que ver con la libertad y la apertura, en cuanto opuestas al encierro en la rigidez autodefensiva. El Papa lo dice a propósito del evangelizador, pero pienso que -también este desafío- vale para el teólogo. "Vemos así que la tarea evangelizadora se mueve entre los límites del lenguaje y de las circunstancias. Procura siempre comunicar mejor la verdad del Evangelio en un contexto determinado, sin renunciar a la verdad, al bien y a la luz que pueda aportar cuando la perfección no es posible. Un corazón misionero sabe de esos límites y se hace "débil con los débiles [...] todo para todos» (1 Co 9, 22). Nunca se encierra, nunca se repliega en sus seguridades, nunca opta por la rigidez autodefensiva. Sabe que él mismo tiene que crecer en la comprensión del Evangelio y en el discernimiento de los senderos del Espíritu, y entonces no renuncia al bien posible, aunque corra el riesgo de mancharse con el barro del camino" (EG 45). "Más que el temor a equivocarnos, espero que nos mueva el temor a encerrarnos en las estructuras que nos dan una falsa contención, en las normas que nos vuelven jueces implacables, en las costumbres donde nos sentimos tranquilos, mientras afuera hay una multitud hambrienta y Jesús nos repite sin cansarse: «iDenles ustedes de comer!» $(M c 6,37)$ ” (EG 49). Si el evangelizador -y el teólogo- debe ser libre, es porque la Palabra de Dios, a la que sirve, es libre: "La Palabra tiene en sí una potencialidad que no podemos predecir. [...]. La Iglesia debe aceptar esa libertad inaferrable de la Palabra, que es eficaz a su manera, y de formas muy diversas que suelen superar nuestras previsiones y romper nuestros esquemas" (EG 40). "En su constante discernimiento, la Iglesia también puede llegar a reconocer costumbres propias no directamente ligadas al núcleo del Evangelio, algunas muy arraigadas a lo largo de la historia, que hoy ya no son interpretadas de la misma manera y cuyo mensaje no suele ser percibido adecuadamente. Pueden ser bellas, pero ahora no prestan el mismo servicio en orden a la transmisión del Evangelio. No tengamos miedo de revisarlas. Del mismo modo, hay normas o preceptos eclesiales que pueden haber sido muy eficaces en otras épocas pero que ya no tienen la misma fuerza educativa como cauces de vida" (EG 43). En un pasaje se refiere explícitamente a la libertad de la teología y del pensamiento en general:

"Las distintas líneas de pensamiento filosófico, teológico y pastoral, si se dejan armonizar por el Espíritu en el respeto y el amor, también pueden hacer crecer a la Iglesia, ya que ayudan a explicitar mejor el 
riquísimo tesoro de la Palabra. A quienes sueñan con una doctrina monolítica defendida por todos sin matices, esto puede parecerles una imperfecta dispersión. Pero la realidad es que esa variedad ayuda a que se manifiesten y desarrollen mejor los diversos aspectos de la inagotable riqueza del Evangelio" (EG 40).

El desafío para el teólogo es, a mi parecer, aceptar la libertad de la Palabra, que siempre lo supera, y estar, por lo tanto, siempre abierto, sin encerrarse nunca en sus posiciones, dispuesto a enriquecerse permanentemente en el diálogo con otros, a revisar una y otra vez lo ya sabido, a dejar de lado lo acostumbrado y seguro. Pero no por un afán de novedades sino por fidelidad a la Palabra, que interpela desde la realidad y desde la Escritura y la vida de la Iglesia. 
